\title{
Seeing is not believing
}

Clear demonstrations of gender bias may not be enough to change attitudes. Researchers examined hundreds of online responses to reports of a study that showed experimental evidence of gender bias in science faculty members. Comments that

Cognitive psychologist William S. Horton studies language at Northwestern University in Evanston, Illinois. But last October, he did something unusual - he co-authored a paper that had failed to replicate some of his earlier results. He explains that it was a tough decision, but has had a positive outcome.

\section{What are your research interests?}

As a graduate student, I worked on language use in conversations with a researcher who was investigating whether effective communication requires consideration of shared information. He found evidence that people are egocentric and initially give more weight to their own knowledge in conversations with others, and make language adjustments only later on the basis of feedback. As a postdoc, I had worked with someone who believed that we always keep track of 'common ground' or shared knowledge and are not egocentric initially. I developed a model that bridges both perspectives.

\section{How did your research evolve?}

I started to look at the role of memory in how people establish common ground in conversations. I showed that common ground need not be a conversation goal because other people can function as cues to retrieve relevant experiences from memory (W. S. Horton Lang. Cogn. Process 22, 1114-1139; 2007).

\section{Was it controversial?}

There wasn't a strong reaction one way or another. Sarah Brown-Schmidt, a psychologist at the University of Illinois at Urbana-Champaign, wanted to build on my memory theory in her research. She recreated the experiment, but it did not replicate my results. I gave her my materials so that she could try again. That experiment failed, too, and she asked me to be a co-author in a failure-to-replicate paper.

\section{Were you worried about doing so?}

The main con was putting my name on a publication that called my earlier work into question. On top of that, I was concerned about how I would talk about this result and what it would mean for my career. The decision would have been much harder had I not yet had tenure. The pros were that it was the right thing to do and that I would be able to help to put the finding into context. Sarah and I both had a sincere interest in making clear that although this study didn't replicate my results, the idea still has worth.

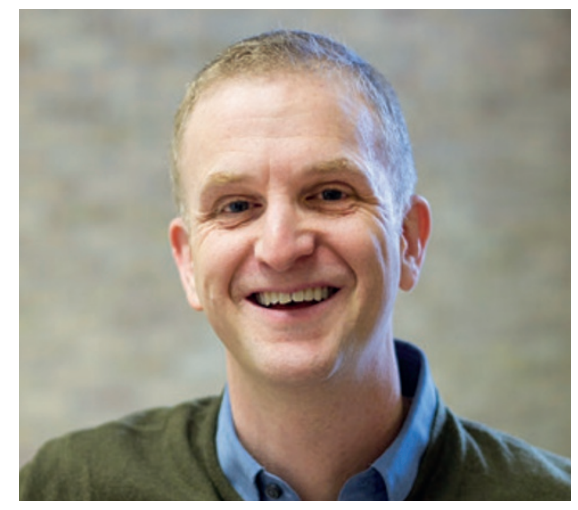

What did the failure-to-replicate study find? We found no evidence that memories established in the context of other individuals helps in the recognition of shared information during subsequent interactions.

\section{You have had a positive response to the} publication. Was that surprising?

Yes. The journal I originally published in chose not to review it, so we went to PLoS ONE (S. Brown-Schmidt and W. S. Horton PLoS ONE 9, e109035; 2014) which encourages the publication of negative results. The study got picked up on Twitter, Reddit and $\mathrm{CBC}$ radio. I was surprised that others found it so noteworthy.

\section{Do you think that more researchers should} publish the findings of replication attempts? There is an increasing effort, at least in psychology, to document replications in opensource databases, such as the Reproducibility Project. Some top-tier psychology journals have adopted pre-registration reporting, in which the methods and data-analysis plans are reviewed before replication is attempted, to smooth the review process. To what extent the original author is part of that process is pretty open.

\section{Will you try again to validate your theory?}

I still very much believe in it and have other results that support it, but I may look for new ways to address the same questions.

\section{Where do you go from here?}

I'm interested in seeing how this paper gets cited. I believe in the accumulation of findings. Not every result is going to hold up. That's just how science works. either justified bias or denied its existence were three times more likely to come from men than from women (C. A. MossRacusin, A. K. Molenda and C. R. Cramer Psychol Women. Q. http://doi.org/zqn; 2015). Initiatives to combat gender and other bias will need to do more than offer proof that it exists, says lead investigator Corinne Moss-Racusin at Skidmore College in Saratoga Springs, New York. "We need to understand whether people are open to that evidence."

\section{PHD TRAJECTORIES}

\section{Data wanted}

A report from the US Council of Graduate Schools (CGS) in Washington DC calls for graduate schools to collect data on the careers of their $\mathrm{PhD}$ graduates. Such information is essential to shape programmes to help graduates to establish fulfilling careers, yet only one-third of institutions collect such data formally, concludes Understanding PhD Career Pathways for Program Improvement. Specifically, institutions should cooperate to develop standards and methods to track alumni careers. The publication comes at a time of growing concern about job prospects. "We hope it will be a launching pad for some real action," says CGS director of research Jeff Allum.

\section{DOCTORAL PROGRAMMES}

\section{Online self-help}

The European University Association (EUA) in Brussels has released a prototype of an online self-assessment tool for institutions with doctoral programmes. The aim is to help university leaders to decide how best to engage the international research community. Built with input from dozens of institutions, the tool can support cross-institutional discussions on strategies to build cross-country collaborations or boost international opportunities, says EUA's Thomas Jørgensen. For instance, programmes hoping to recruit more international students could be prompted to first assess their capacity for handling visas. A final version should be available in September. 